\title{
La solitaria oscuridad del padre. El Dios de las tinieblas en la Oratio de dignitate hominis de Pico della Mirandola
}

\author{
María José Vega \\ Universitat Autònoma de Barcelona
}

El tema principal de la Oratio de dignitate hominis de Pico della Mirandola no es la dignidad del hombre, como induce a creer el título que le concedieron sus editores, sino la unión mística con la divinidad a través de recorridos tripartitos, mediante un ascenso iniciático y un proceso de conocimiento y superación de artes y ciencias que culmina en la felicidad teológica. El hombre ha de desdeñar las cosas terrestres, despreciar las celestes, aspirar a las ultramundanas, imitar la curia eminentísima de los Tronos, Querubines y Serafines. Logrará así recogerse en la unidad de su propio centro, hacerse uno con el espíritu de Dios, anegarse en fin en la cegadora tiniebla de la divinidad, en la solitaria oscuridad del Padre: in solitaria Patris caligine. Conviene recordar este pasaje:

Et si nulla creaturarum sorte contentus in unitatis centrum suae se receperit, unus cum Deo spiritus factus, in solitaria Patris caligine qui est super omnia constitutus omnibus antestabit.

Este Dios en la tiniebla no es el único Dios de la Oratio: la visión última de la divinidad es también la culminación de un proceso de conocimiento que se cifra en metáforas de la luz. Con la ciencia moral, explica Pico, el alma purifica los ojos; con la dialéctica, aprende a fijar la mirada; con la contemplación de la naturaleza, se acostumbra a la luz de la verdad, que, no obstante, es aún débil, como la del sol cuando nace: quasi nascentis solis incunabula. Sólo entonces la teología y el culto nos conceden la fuerza necesaria para que podamos mirar con los ojos abiertos, como las águilas del cielo, el fulgor resplandeciente del sol meridiano.

In solitaria caligine Patris. A pesar de la celebridad alcanzada por la Oratio de Pico, esta expresión no ha merecido hasta ahora la atención de sus comentadores, ni por la naturaleza de la imagen, ni por la aparente paradoja de que Dios sea, en el mismo texto, sol y tiniebla, ni por la audacia de la hipálage, en cuya caligo solitaria late quizá el recuerdo de la célebre de la Eneida, la sola sub nocte relativa a los fugitivos de Troya. Algunos se limitan únicamente a manifestar su sorpresa ante este Dios tenebroso y a contrastar esta imagen con las más 
frecuentes, que cifran la divinidad en la luz, o que se refieren a ella con metáforas solares. Sólo Albino Biondi observa que «Pico amaba la metáfora del Dios-tiniebla», y sugiere que quizá esta solitaria oscuridad que culmina el trayecto espiritual de la Oratio pueda entenderse a partir de un verso del psalterio: aquel que recuerda la terrible condición de Dios, el que "hizo de las tinieblas su velo, de las tenebrosas aguas su tienda» (posuit tenebras latibulum suum, in circuitu eius tabernaculum eius, tenebrosa aqua in nubibus aëris, Ps. 17:12). ${ }^{1}$

Ahora bien, este Dios tenebroso, o, más precisamente, el Dios caliginoso de Pico, no está tan cercano al del salmista como al de Moisés, al Dios del encuentro en el Sinaí tal como lo relata el libro del Exodo. Allí, según la narración veterotestamentaria (Ex. 20:21): «Stetitque populus de longe. Moyses autem accessit ad caliginem in qua erat Deus».

Es posible que la solitaria caligo de Pico descienda en última instancia de este pasaje del Éxodo, aunque no sin mediaciones. La memorable imagen escrituraria, la de la tiniebla que alberga a Dios, fue racionalizada por las sucesivas interpretaciones de la vida de Moisés y de su significado simbólico y místico. Gregorio de Nisa, en la Vita Moysis (clxii-clxiii), había señalado que el acceso de Moisés ad caliginem representa la naturaleza incognoscible de la divinidad, su condición invisible para el hombre, y sugiere también que las tinieblas del Dios mosaico deben leerse junto con un pasaje de Juan (1: 18), en el que se afirma que nadie, nunca, ha visto a Dios: Deum nemo vidit unquam. Dios aparece primero en la luz y después en la tiniebla: el texto nos enseñaría con ello que el conocimiento es luz para el que lo recibe, pero a medida que el espíritu asciende en perfección, ve cada vez con mayor claridad que la naturaleza divina es invisible. San Gregorio detalla un proceso por el cual el alma emprende una búsqueda intelectual y se interna en sí misma, hacia su centro, hasta adquirir el verdadero conocimiento, que reside en ver por el no ver, porque lo incomprensible está como envuelto en tinieblas. ${ }^{2}$ En el Comentario del Cantar de los Cantares, indica además que lo que la Esposa llama el lecho debe entenderse como la más perfecta participación en Dios, y lo que llama noche, como el tiempo de la oscuridad: la noche mostraría, de creer a Gregorio, que la Esposa ha logrado la contemplación de lo que no puede verse, y que se halla, "como Moisés en el Sinaí», en "la oscuridad de la presencia de Dios».

Moisés es, además, relevantísimo en la obra de Pico della Mirandola. A Moisés se le atribuye la escritura del Génesis, y a las palabras con las que relata los seis primeros días de la creación dedicó Pico los siete libros del Heptaplus, quizá su obra más ambiciosa. Con una invocación a Moisés y a Timeo, esto es, al relato creacional hebreo y al platónico, para celebrar las concordancias

1. Giovanni Pico Della Mirandola, Conclusiones Nongentae. Le novecento tesi dell'anno 1486, Albino BiOndi (ed.), Firenze: Olschki, 1995, xxv, n. 49.

2. Véase Guillermo SERÉS, La transformación de los amantes. Imágenes del amor de la Antigüedad al Siglo de Oro, Barcelona: Crítica, 1996, p. 29 ss., sobre la contemplación divina de Moisés y la tradición que concibe la unión contemplativa a través de la oscuridad, entre cuyos descendientes se cuenta la noche oscura de San Juan. 
entre ambos, se abre la Oratio de dignitate hominis. A la lectura mística de los tres ámbitos del templo de Moisés acude poco después para encontrar paralelos de los itinerarios tripartitos que conducen a Dios, que constituirían una revelación común que se oculta en cada religión bajo símbolos diversos. También en la Oratio, como hará en la Apologia, se refiere Pico al encuentro del Sinaí, que es el hecho fundante de la tradición cabalística, de la que se jacta de haber sido el primero en hablar latinamente (vera cabala de qua credo me primum apud latinos explicitam fecisse mentionem): Pico ha leído en Esdrás, en un tratado de Hilario sobre el salmo II y en los comentarios de Orígenes al Evangelio de Juan que la revelación del Sinaí fue doble. En el largo coloquio de la divinidad con su sacerdote, Moisés no sólo recibió las tablas de la ley, que habían de darse al pueblo, sino también enseñanzas secretas que no podían ser divulgadas. Esa doctrina - mysteria secretiora, divinitatis archana - constituye una sabiduría oculta que no puede trasladarse a la escritura, en la que han de iniciarse setenta sabios que, a su vez, la revelarán a otros setenta de la generación siguiente. Y así hasta que Esdrás, temiendo por la suerte de estos misterios en las vicisitudes del exilio y las guerras, violara la orden de Dios y las pusiera por escrito: fueron éstos, dice Pico, los libros de la cábala (hi sunt libri scientiae cabalae), ciencia que habría nacido en la revelación del Sinaí, la más antigua de las teologías, la que figura con un lugar de honor en las Conclusiones Nongentae y en la Oratio, y por la que Moisés es «fuente de inteligencia inefable» (sacrosanctae et ineffabilis intelligentiae fontana).

Que el Dios de la Oratio de Pico sea, a la vez, lux meridialis y el Dios del Sinaí, el que habita en la oscuridad, no ha de entenderse como una contradicción o una inconsistencia. El Dios de las tinieblas de Pico es también cifra del Dios velado, el Deus absconditus, frente al Dios que se manifiesta a los hombres. En la mística hebraica, el Dios desconocido es aquel que no puede ser contemplado, ya que todo conocimiento de Dios por parte de la criatura se fundamenta en la relación que Dios ha elegido mantener con ella. ${ }^{3}$ El Dios oculto es el Dios en sí mismo, como ser absoluto, y no el que escoge revelarse en los textos sagrados, que es el Dios de la religión y el de los muchos nombres. Acceder al Dios de las tinieblas es acceder a la esencia misma de Dios, la que se vela, la que elige no revelarse, al Dios-Dios, no al Dios manifiesto: al último centro de la divinidad, absolutamente y en sí misma. Es el Deus absconditus de los místicos, la última raíz de Dios, o la raíz de la raíz, como preferían decir los cabalistas españoles, a quienes Pico, de atender a Lelli y a Wirszubski, tuvo por maestros. ${ }^{4}$

3. Sobre el Deus absconditus de la cábala, véase Gershom SCHOLEM, Le grandi correnti della mistica ebraica, Torino: Einaudi, 1993, p. 28 s.

4. Pico se cuenta entre los primeros cabalistas cristianos. Sobre su conocimiento de la mística hebraica y en particular del Zohar, y sus relaciones con judíos españoles, vid. Fabrizio LeLLI, "Yohanan Alemanno, Giovanni Pico della Mirandola e la cultura ebraica italiana del XV secolo», en Giancarlo Garfagnini (a cura di), Giovanni Pico della Mirandola. Convegno internazionale di studi nel cinquecentesimo anniversario della morte (1494-1994), Firenze: 
La Oratio de dignitate hominis propone pues ascender de la luz querúbica de la contemplación al fuego seráfico del amor: las metáforas luminosas de los órdenes superiores de las jerarquías celestes parecerían anunciar su sobrepujamiento final en una luz mayor. Esa luz cegadora, en suma, de la que es cifra imperfecta la metáfora del sol meridiano. Pero el sol meridiano, al que pueden mirar con los ojos abiertos los hombres que devienen águilas celestes, es el Dios que se revela, el que se muestra a su criatura, el que puede ser contemplado; por ello, es la tiniebla mosaica, la caliginosa y solitaria oscuridad del Padre, el Dios escondido, el que culmina y cierra la experiencia mística que propone la Oratio.

\section{Nota}

Ya Eugenio Garin había hecho notar que la edición príncipe de la obra de Giovanni Pico no concedía título alguno al breve discurso que, con el tiempo y los editores, terminaría por conocerse como Oratio de dignitate hominis. En la tabla general de las ediciones boloñesas de principios del siglo XVI, la obra aparece mencionada, de forma sucinta y poco comprometedora, como una Oratio quaedam elegantissima, subrayando así, únicamente, su excelencia estilística y la ejemplaridad de su elocuencia. Pico, en una carta a Girolamo Benivieni, se refiere a un fragmento de su discurso como una oratio ad laudes philosophiae: es éste quizá el título que podría considerarse como más adecuado, por ser el único que procede de su autor, a pesar de que la referencia epistolar es circunstancial y se hizo antes de concluir la redacción del texto definitivo. Los editores modernos de la Oratio no han reparado en que en la edición príncipe — esto es, la edición boloñesa que estuvo al cuidado de Giovanfrancesco Pico, sobrino y albacea literario del autor- y a pesar de que el texto carezca de epígrafe, las cabeceras reproducen un título inequívoco: Oratio in coetu Romanorum, esto es, Discurso a la asamblea romana. Giovanfrancesco Pico abandonó esta cabecera en 1517, en la última de las ediciones venecianas que estuvieron a su cargo. ${ }^{5}$ Frente al énfasis en el estilo de oratio elegantissima, o a algunos aspectos del contenido de oratio ad laudes philosophiae, el título de la cabecera, oratio in coetu Romanorum, se refiere al hecho de que, efectivamente, el discurso que la historiografía contemporánea acabaría por convertir en «manifiesto» del Renacimiento, se concibió como la prolusión al debate público sobre las novecientas tesis que debería haberse celebrado en Roma en la epifanía de 1486 y que habría de reunir, a expensas del conde mirandolano, a todos los sabios de Europa que quisieran participar en él.

El título de hominis dignitate pudo proceder de los primeros epígrafes marginales de la edición boloñesa (a saber, los siguientes: Abdallah, Mercurius, dig-

Olschki, 1997, I, p. 303-326; Ch. WIRSZUBSKI, Pico della Mirandola's Encounter with Jewish Mysticism, Cambridge Mass. \& London, 1989.

5. Stephen Alan FARMER ha llamado la atención sobre este hecho en sus estudios on-line (2000) sobre las Conclusiones Nongentae: vid. www.safarmer.com/pico/oration. 
nitas hominis, al que siguen otros muchos, que indican, en cada momento, el tema del discurso). El primer epígrafe significativo (dignitas hominis) habría migrado, por así decir, al título, ${ }^{6}$ y este hecho se habría visto favorecido por la falta de un nombre temático para el texto y por la indefinición (oratio quaedam...) del que había elegido el primer editor. Cabe recordar que las Conclusiones no se imprimieron con la obra de Pico (al menos, no hasta 1557), lo que habría propiciado la descontextualización completa de la Oratio y, como corolario, habría agudizado la necesidad de concederle un título que constituyera, de algún modo, una indicación para su lectura. El título de hominis dignitate aparece ya en una reimpresión pirata y plagada de errores de las Opera de Pico, la que apareció en 1504 en las prensas de Estrasburgo, en el taller de Jacob Wimpheling y Hyeronimus Emser. No tuvo éxito inmediato, si bien convivió con otros semejantes (por ejemplo, Opusculum de homine, Oratio de homine in qua sacra philosophia explicantur...) y sólo acabó por imponerse a finales del siglo XVI.

La cuestión del título no es baladí, porque genera expectativas y orienta una dirección de lectura. Publicar la Oratio era perpetuar el recuerdo de las Conclusiones, que el editor y sobrino de Pico había decidido omitir de las Opera omnia y que contenían las proposiciones suspectas que habían forzado el examen papal de la obra. De hecho, allí el texto comparece como una de las obras juveniles y menores, levioris curae, del autor. La publicación independiente del discurso propició una lectura totalmente descontextualizada de lo que en realidad era una prolusio a un acto de disputa académica. Los historiadores y críticos han leído habitualmente la Oratio al margen de las Conclusiones, siguiendo por tanto las intenciones del editor y no las del autor: inducidos por el título, han privilegiado el concepto de dignitas hominis que aparece brevemente en el proemio de la Oratio. Quizá no sobre, por ello, recordar aquí que, en el texto de Pico (dejando a un lado los títulos y epígrafes marginales de los editores), la palabra dignitas sólo aparece dos veces, y ninguna de ellas para referirse al hombre (la referencia es, en el primer caso, a la vida querúbica, y concierne, por ello, y únicamente, a la dignidad de la que están investidas las jerarquías angélicas).

La Oratio de Pico se abre, ciertamente, con una exposición de la excelencia humana: el hombre es principio de comunicación entre las criaturas, familiar de las superiores y soberano de las inferiores; por la perspicacia de sus sentidos, el poder de la razón y la lumbre de la inteligencia, es intérprete de la naturaleza; es intersticio entre la estabilidad de lo eterno y el devenir del tiempo, y, como habrían dicho los persas, cópula e himeneo del mundo, apenas inferior a los ángeles. Este celebradísimo comienzo es, sin embargo, un comienzo oblicuo, porque Pico añade a continuación: «tales cosas no me satisfacían plenamente». Así pues, el tema de la dignidad humana que reconoció el redactor

6. Es ésta la hipótesis de Stephen Alan FARMER, Syncretism in the West: Pico's 900 theses (1486). The Evolution of Traditional Religious and Philosophical Systems, Tempe, 1998, 19 n. 50. 
de los epígrafes marginales comparece en efecto en la Oratio, en términos no desemejantes a los que habían usado antes Giannozzo Manetti o Marsilio Ficino. Pico, de hecho, no reclama originalidad para tales palabras: han sido dichas muchas veces y por muchos (a multis) y enuncian, ciertamente, cosas grandes, pero no las más importantes (magna haec quidem, sed non principalia). Presume pues la familiaridad de su auditorio con los argumentos señalados — que conciernen al hombre, sin que la palabra dignidad haya aparecido nunca - para matizar inmediatamente su adhesión a ellos: con ser todos ciertos y relevantes, viene a decir, no enuncian ni entrañan la cuestión principal, que es la que procede a exponer en el discurso y constituye su tema dominante. 